Original Research

\title{
Water Consumption Demarketing Strategies with Reference to the Gaza Strip, Palestine
}

\author{
Mohammed Z. Salem ${ }^{1 *}$, Samir Baidoun², Rania F. Almuzaini ${ }^{3}$ \\ ${ }^{1}$ Department of Business and Finance Management, University College of Applied Sciences (UCAS), \\ Gaza City, Palestine \\ ${ }^{2}$ Department of Business Administration, Birzeit University, Ramallah City, Palestine \\ ${ }^{3}$ Department of Planning and Information Systems, University College of Applied Sciences (UCAS), \\ Gaza City, Palestine
}

Received: 5 May 2017

Accepted: 31 May 2017

\begin{abstract}
It is widely recognized that many countries are entering an era of severe water shortage. The Gaza Strip (GS) in Palestine is among regions with the scarcest water resources and where supplies barely meet the needs of the population. Priority in resolving this problem has always been given to reducing water consumption. Very few previous studies have reported on using the "demarketing" approach to enhancing water conservation practices, with none taking place in Palestine. Thus, this empirical study aims to identify the main items of the marketing mix for demarketing water consumption in the GS in an attempt to alleviate the water shortage problem. A questionnaire was developed to collect primary data regarding factors affecting the demarketing of water consumption in the GS. The questionnaire was distributed to 400 users who were randomly selected. Findings of this study suggested prioritizing strategies based on the mean values of each marketing mix factor. A promotion strategy designed to create awareness concerning the economic and social benefits of demarketing water consumption was ranked first, while other strategies related to water distribution (place), price, and product were ranked second, third, and fourth, respectively. Implications for decision- and policymakers were stated as prioritized interventions for each strategy according to the respondents' answers.
\end{abstract}

Keywords: water consumption, demarketing, supply-demand balance, Gaza Strip

\section{Introduction}

The rapid increase in urban water demands presents a great challenge for water supply utilities in terms of regularly providing for the growing world population, as it has been estimated that by 2020 water shortages will be

*e-mail: mrdd_salem@hotmail.com a serious worldwide problem [1-2]. The Middle East and North Africa region (MENA) - home to $6.3 \%$ of world's population - is the most water-scarce region in the world, accessing only $1 \%$ of the earth's accessible freshwater resources [1].

Palestine is among countries with the scarcest water resources in the world, and supplies barely meet the needs of the population. In the GS specifically, water sources are extremely stressed and freshwater is becoming increasingly insufficient. It has been argued that average 
domestic water consumption in the GS is estimated at 79 liter/capita/day [3]. Since the population continues to increase at a very high ratel, the per capita water availability is projected to fall drastically in the near future [1]. Furthermore, water supply systems (piped urban systems) in the GS are designed to deliver water "on demand." This means that the system operators have no direct control over the quantity of water taken from the system by customers, hence worsening an already stressed water situation.

Past research and experience have indicated that appropriate water-demand management policies can improve the existing supply-demand balance in waterstressed regions and also offer multiple benefits to all stakeholder groups. A common water-demand management practice used to resolve the water challenge is reducing water consumption, since it is the cheapest and safest way to preserve water resources [5].

One little-known concept that can be utilized for reducing water consumption is demarketing. Demarketing simply refers to dissuading customers from consuming or buying some products, either because they are harmful or simply because consumer demand exceeds supply [6].

Demarketing in literature has been investigated in light of the 4 Ps of the marketing mix (product, price, place, and promotion) originally proposed by McCarthy. Few previous studies have investigated demarketing techniques and strategies to enhance water conservation practices [7]. In some regions, pricing strategies (applying charges for water consumption) have been proven to motivate water conservation practices among consumers [8-9]. Other studies that have investigated promoting sustainable residential water consumption have concluded that the potential of demarketing should be determined in order to link awareness to behavior [10-11]. It is evident that there is a semi-consensus among researchers in different regions about many of the factors affecting the demarketing of water consumption.

\section{Subjects and Methods}

\section{Domestic Water Supply and Demand Situation in the Gaza Strip: an Overview}

The GS happens to be the most densely populated area in the world, with an estimated population of 1.8 million people within a total area of $365 \mathrm{~km}^{2}$ [4]. Due to high birth rates, the population is expected to increase to 2.1 million by 2020 . This population is currently facing an extreme water scarcity and is globally rated the second most water deprived after Kuwait, were supplies barely meet the demands [12]. Even though the total volume available to the domestic

1 The Gaza Strip's population growth rate is 3.4\% annually, which is one of the highest worldwide and is expected to continue in the coming years [4]. water supply (98 MCM) indicates a relatively high per capita use of around 170 liter/capita/day, this figure can be misleading since it doesn't take into account the "real losses" in the water distribution network, which are estimated at $44 \%$; thus reducing the total domestic water supply to $43 \mathrm{MCM}$ and, consequently, the per capita consumption rate to 95 liter/capita/day. This figure is also considered inaccurate since more than $90 \%$ of the domestic water supplied is of very poor quality as the amount of water extracted from the coastal aquifer is three times more than that recommended to sustain the aquifer for future use [3]. The per capita daily consumption rates in the GS vary widely depending upon which source is to be believed. Figures provided range 70-170 liter/capita/ day $[13-17]^{3}$. Recent balance records have also indicated a water deficit of $80 \mathrm{MCM}$, which is expected to grow to approximately $100 \mathrm{MCM}$ by 2020 [18]. Moreover, only $25 \%$ of the total GS population is accessing water on a daily basis (six to eight hours per day), while the remaining inhabitants receive water once every two to four days [19].

Water stress in Palestine in general and GS in particular long has been associated with geopolitics. This includes - but is not limited to - Israeli policies restricting Palestinian control over their water resources [20], the tightened blockade imposed on the GS since 2007, and Israeli military operations carried out in the GS since 2000.

Other influencing factors include over-extraction of the coastal aquifer (the main source of water in the GS), seawater intrusion, and climate change, as there is an alteration in the quantities of rainfall and periods of heavy precipitation [21-22]. This alteration has substantially reduced the aquifer's capacity to recharge itself.

\section{Water Deficit Coping Mechanisms Developed in the GS}

The Palestinian Water Authority (PWA) developed a water-demand management plan providing nonconventional water resources in the GS. This includes water desalination, wastewater reuse, and stormwater harvesting in order to gap the water deficit encountered regionally. However, the PWA is constantly facing

2 "Real Losses" is defined by the U.S. Environmental Protection Agency (EPA) as the physical leaks that consist of leakage from transmission and distribution mains, leakage and overflows from utility storage tanks, and leakage from service connections up to and including meters.

3 Discrepancies in these estimates can most likely be attributed to methodological differences among studies. For instance, the World Bank argues that other studies fail to take into account the water lost in piped network transit, which accordingly tends to make water availability data high [16]. Consequently, in accounting for these losses they produce an estimate at the bottom end of the range: $701 / \mathrm{c} /$ day in the Gaza Strip [13]. 
challenges during the implementation of these strategies basically due to the limited resources and the uncertain political environment [23]. Additional water-demand management practice include applying charges for water consumed (metering water). This practice has proven validity in some regions in terms of reducing any unnecessary water consumption in some regions [8-9, 24-25]. However, in the GS this has proven to be inadequate since the majority of the local population tends not to pay the water charges. This is due to numerous reasons, including a culture of non-payment, poverty, lack of understanding of water economics, and poor water services.

As for the local population, coping mechanisms have developed, including mainly the use of private unlicensed wells and small-scale desalination ${ }^{4}$. However, the rapid expansion of these wells (drilled for domestic supply purposes) has significantly contributed to the long-standing degradation of the coastal aquifer and consequently has reduced water quality drastically ${ }^{5}$. Other options involved constructing desalination plants to produce water. However, water produced this way tends to be costly as the standard rate for trucked water is four to five times the price of piped water, or around 12 NIS (US\$3.3) per cubic meter [16]. It has further been estimated that the average urban family in the GS spends $8-16 \%{ }^{6}$ of its total household income on water bills [16]. Additionally, household water supply expenditures are expected to increase by as much as $30 \%$, while quantities available for human consumption will be inadequate [19]. This water crisis is projected to considerably increase if no further sustainable demand management strategies are utilized.

\section{Demarketing Concept and Types: an Overview}

The concept of demarketing was initially proposed by Kotler and Levy in 1971. They defined demarketing

4 At least 40 private desalination plants (only 20 of these plants are licensed by PWA) sell both wholesale by tanker and retail by jerrycan, producing about 2,000 m3 a day. There is no monitoring available for the distribution system of these plants as hundreds of trucks transport and distribut this desalinated water and thousands of small tanks exist at the small shops. Water produced by such plants lacks basic minerals since the majority of minerals are removed by the reverse osmosis process.

5 Poor water quality is due to increased salinity and high concentrations of nitrates (compounds that are difficult and costly to remove from drinking water supplies). It has been estimated that only $5-10 \%$ of water supplied through the network is fit for human consumption [16]. The United Nations predicts that Gaza's potable water supply will be completely depleted within the next 15 years [14].

6 The discrepancies in these estimates can most likely be attributed to the degree of reliance on trucking. as "that aspect of marketing that deals with discouraging customers in general or a certain class of customer in particular on either a temporary or permanent basis" [26]. In addition, demarketing (in a social marketing context) can also be defined as having the objective to decrease demand by discouraging consumption or use of products such as alcohol and cigarettes that pose a health risk [27]. According to Gupta [28], demarketing can be defined as marketing aimed at limiting growth, practiced, for example, by governments to conserve natural resources or by companies unable to serve adequately the needs of all potential customers. From the researcher's point of view, it is noted that there is consensus regarding the meaning of demarketing based on the definition of Kotler and Levy [26].

Kotler and Levy [26] recommend that organizations need to specifically demarket their items to manage temporary deficiencies and excess requests, and also lessen requests from "undesirable sections." Hence organizations and/or governments should precisely identify the marketing mix elements (product, price, place, and promotion) to achieve the demarketing goals and manage their association with customers [29].

Kotler and Levy [26] have distinguished three main types of demarketing:

- General demarketing is utilized by an organization (or government) when everyone is targeted for the demarketing purposes and when the demand is too high. In other words, reducing demand across the board.

- Selective demarketing is utilized when an organization is seeking to reduce demand within certain segments of the market among specific types of consumers. This is usually where one market is less profitable than other markets for the product.

- Ostensible demarketing is utilized by the manufacturer intending to increase customer attention and thus demand, but while appearing to discourage demand. This relies basically on the principle that customers will be attracted as the product becomes harder to obtain.

\section{Research Framework}

In this study, the original work of Kotler and Levy [26] regarding input analyses was utilized in constructing the research model, which is partially normative and partially descriptive, as can be seen in Fig. 1. The proposals of Kotler and Levy [26] are partially evident in the normative part of the model. However, the researchers are responsible for the descriptive part upon which the hypotheses of this study was based. It has been argued that the Kotler and Levy [26] article about demarketing in 1971 was purely theoretical and that there is a need for careful research to verify and clarify their ideas [29]. 
Inputs (Independent variables) Outputs (Dependent variable)

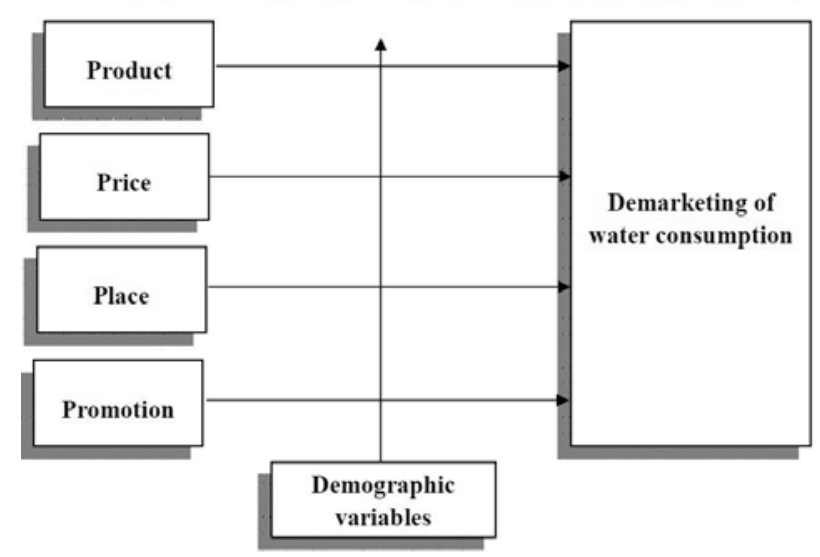

Fig. 1. Research framework.

\section{Method}

Participants

In total, 400 users from the Gaza Strip participated in the study. The majority of respondents were aged 21-30, and the smallest group of respondents were aged 20 years or less. Male gender accounted for $63.5 \%$ $(\mathrm{n}=254)$ of participants while female gender constituted $36.5 \%$ of participants $(n=146)$. The majority of respondents were bachelor degree holders and the smallest group of respondents were high school or lower degree holders. Most respondents were married and the smallest group of respondents were divorced. The majority of respondents has a monthly salary of 1,500 NIS or less and a small percentage of respondents have a monthly salary of more than 4,501 but less than 5,500 NIS.

\section{Procedure}

A questionnaire was developed to investigate factors affecting the demarketing of water consumption in the GS from the user point of view. The sample size for the questionnaire was determined using the following formula [30]:

$$
N=\frac{N P}{1+\left(N P \times e^{2}\right)}
$$

$\mathrm{N}$ : sample size, NP: population size, e: the errors term $=0.05$

According to the literature, a sample size (with 5\% margin of error) of 384 could be used in large populations. Sample size in this research is 400 , hence an increased level of certainty is achieved. Forty-six out of the 400 users selected to participate in this research refused to participate for various reasons. Another 11 who initially agreed to participate didn't answer most of the questions or refused to answer the full questionnaire when they first saw it. Despite these difficulties, the researchers redistributed the 57 questionnaires to obtain a total sample size of 400 respondents.

\section{Measures}

The researchers developed a questionnaire to investigate factors affecting the demarketing of water consumption in the GS from the user point of view. The questionnaire basically included 21 items organized as follows: personal information (five items, questions from Q1.1 to Q1.5), product (four items, questions from Q2.1 to Q2.4), price (four items, questions from Q3.1 to 3.4), place (four items, questions from Q4.1 to Q4.4), and promotion (four items, questions from Q5.1 to Q5.4). The participants were asked to respond on a five-point Likert scale $(1=$ strongly disagree, 2 = disagree, $3=$ no opinion, $4=$ agree, and $5=$ strongly agree). Additionally, the questionnaire was reviewed and evaluated by marketing specialists (academicians and practitioners). The researchers have modified, deleted, and added the necessary parts of the questionnaire in response to the received feedback.

Content validity for this study was conducted by comparing the measurement items of each variable with an extensive review of the literature related to the marketing mix and demarketing of water consumption (policymaker strategies to reduce water consumption); measures used in this study were capable of capturing the 4Ps. For construct validity, this was confirmed by conducting principal components factor analysis.

For this study, the questionnaire was piloted among 40 participants to secure content clarity on words and formatting and to calculate content reliability. As for reliability, an internal consistency for the four factors (product, price, place, and promotion) was calculated using the reliability coefficient Cronbach's alpha. This was indicative of the factor validity of the measurement instrument where Cronbach's $\alpha$ was computed separately for the items of each factor of the 4 Ps. As shown in Table 1, an internal consistency was performed separately for each of the four factors. Cronbach's $\alpha$ values of the 4 factors all exceed the 0.70 standard of reliability for the survey instrument [31]. The results show that all values range between 0.856 and 0.864 , indicating that all scale variables demonstrate an acceptable level of reliability.

\section{Results}

\section{Factor Analysis}

Factor analysis was performed in order to establish the sub-dimensions of the scales consisting of the research questions. In order to determine the factor structure, principal components factor analysis was applied to the scores obtained from the responses given by the 400 participants. In addition, the Kaiser-Meyer-Olkin (KMO) measure of sampling adequacy and Bartlett's test of 
Table 1. Total variance explained and component matrix.

\begin{tabular}{|c|c|c|c|c|}
\hline \multirow{2}{*}{ Item } & \multirow{2}{*}{ MV } & \multirow{2}{*}{ SD } & Component & \multirow{2}{*}{$\begin{array}{l}\text { Cronbach alpha } \\
.944 \text { (for all questions) }\end{array}$} \\
\hline & & & 1 & \\
\hline Product & 3.79 & .675 & & .859 \\
\hline $\begin{array}{l}\text { Q2.1 The policy of programmed water cuts helps to solve the problem } \\
\text { of excess demand of water. }\end{array}$ & 3.86 & .859 & .600 & \\
\hline $\begin{array}{l}\text { Q2.2 The policy of programmed water cuts success depends on the } \\
\text { fairness of applying this policy. }\end{array}$ & 3.79 & .857 & .611 & \\
\hline $\begin{array}{l}\text { Q2.3 Providing clean freshwater at programmed periods of water } \\
\text { supply is an acceptable policy to meet the water supply problem. }\end{array}$ & 3.80 & .869 & .608 & \\
\hline $\begin{array}{l}\text { Q2.4 Excessive consumption of water was a reason to follow the policy } \\
\text { of programmed water cuts. }\end{array}$ & 3.79 & .897 & .501 & \\
\hline Price & 3.88 & .657 & & .864 \\
\hline $\begin{array}{l}\text { Q3.1 Increasing the water price is a good policy for reducing water } \\
\text { consumption. }\end{array}$ & 3.89 & .958 & .619 & \\
\hline $\begin{array}{l}\text { Q3.2 It is preferable to classify water consumption prices based on use } \\
\text { (commercial, industrial, agricultural, and residential). }\end{array}$ & 3.90 & .849 & .578 & \\
\hline $\begin{array}{l}\text { Q3.3 It is preferable to classify water prices according to consumption } \\
\text { levels, applying higher prices for higher levels of consumptions. }\end{array}$ & 3.73 & 1.007 & .696 & \\
\hline $\begin{array}{l}\text { Q3.4 Offering incentives of lower prices to users of lower level of } \\
\text { consumption can contribute to solving the water shortage problem. }\end{array}$ & 4.15 & .742 & .607 & \\
\hline Place & 4.00 & .669 & & .860 \\
\hline $\begin{array}{l}\text { Q4.1 Increasing water sources, including the importing option, could } \\
\text { contribute to solving the water shortage problem. }\end{array}$ & 3.88 & .962 & .605 & \\
\hline $\begin{array}{l}\text { Q4.2 improving the efficiency of water networks to reduce the } \\
\text { percentage of wasted water is crucial for solving the problem. }\end{array}$ & 4.12 & .786 & .748 & \\
\hline $\begin{array}{l}\text { Q4.3 Fair distribution of water according to the number of inhabitants } \\
\text { and their geographical distribution can help solve the problem. }\end{array}$ & 4.05 & .749 & .755 & \\
\hline $\begin{array}{l}\text { Q4.4 Preventing citizens from illegal digging of water wells contributes } \\
\text { to solving the problem. }\end{array}$ & 3.95 & 1.070 & .577 & \\
\hline Promotion & 4.15 & .652 & & .856 \\
\hline $\begin{array}{l}\text { Q5.1 Use a variety of promotional campaigns to explain the economic } \\
\text { and social benefits of reducing water consumption. }\end{array}$ & 4.24 & .847 & .646 & \\
\hline $\begin{array}{l}\text { Q5.2 The launch of promotional campaigns (valuable prizes and gifts) } \\
\text { by the government for consumers who are committed to reducing water } \\
\text { consumption. }\end{array}$ & 4.19 & .840 & .695 & \\
\hline $\begin{array}{l}\text { Q5.3 Promote private sector partnerships (PPP) to improve water } \\
\text { networks and wastewater purification stations. }\end{array}$ & 4.06 & 1.102 & .566 & \\
\hline $\begin{array}{l}\text { Q5.4 Activating the role of concerned institutions to raise consumer } \\
\text { awareness of reducing water consumption. }\end{array}$ & 4.18 & .789 & .729 & \\
\hline
\end{tabular}

sphericity were used to evaluate data appropriateness for factor analysis.

The KMO test checks if the original variables can be factorized efficiently. The KMO index compares the values of correlations between variables and those of the partial correlations. Bartlett's test checks if there is a certain redundancy between the variables that can be summarized with a few factors.

Thus, the KMO value should be higher than 0.50 and the chi-square value of Bartlett's test must be significant at the 0.05 level. The KMO value is 0.821 (higher than the recommended KMO value of 0.50), and Bartlett's test is statistically significant at the $\mathrm{p}<0.00$ level. These results show that the sample can be subjected to PCA in order to uncover the underlying patterns of the independent variables.

In order to present the factor score coefficient matrix estimated by the Principal Components Analysis (PCA) as shown in Table 1, we show one principal factor rotated using the Varimax rotation [32].

Component score coefficient matrix is an output produced by principal components analysis that shows the weighting of variables to be used when computing saved variables of the components. PCA 
is a dimension-reduction tool that is used to identify a smaller number of uncorrelated variables from a large set of data to explain the maximum amount of variance with the fewest number of principle components. Varimax rotation is the most popular orthogonal rotation technique. In this technique, the axes are rotated to maximize the sum of the variances of the squared loadings within each column of the loadings matrix.

The factor consists of 4 constructs (the 4 Ps) of 16 items (questions). According to the literature, a loading value of 0.30 is the suggested minimum level for item loadings on given scales [33-34]. The factor analysis of all measurement items produced factor loadings of more than 0.50 [34]. The results of the analysis did not lead to the removal of any item, and in all cases the factor loadings were higher than the recommended 0.5 minimum. The cumulative percentage of variance explained is greater than the recommended $50 \%$ (Table 1), indicating that the construct validity of scales is supported. Therefore, all factors were acceptably good with a minimum value of $0.501(\mathrm{Q} 2.4$ excessive consumption of water was a reason to follow the policy of a programmed water cut).

\section{Discussion of Findings}

After careful, thorough, and statistical analysis of the data collected, it became evident that the marketing mix elements (product, price, place, and promotion) affect the demarketing of water consumption. As seen in Table 1, the mean values of the $4 \mathrm{Ps}$, (the demarketing factors) reveal that the promotion factor has the highest value (4.15), while the place factor has the second highest value (4.0), and the price and product factors come third and fourth with mean values of 3.88 and 3.79 , respectively. This indicates priorities for decision- and policymakers in developing their strategies and policies to manage the water supply shortages and controlling water consumption levels. The results suggest a prioritized hierarchy (based on the mean values of each item of the demarketing 4 Ps factors) of actions in developing a demarketing strategy of water consumption as follows.

Decision- and policymakers should first target the general public by developing a promotional strategy to raise their awareness concerning the water consumption problem and possible solutions. The strategy should be based on developing awareness campaigns that focus on clearly explaining the economic and social benefits of reducing water consumption. These campaigns should be accompanied by launching rewards to reinforce actions and behaviors related to reducing water consumption by providing valuable prizes and gifts by the government for consumers who are committed to reducing water consumption. A third intervention in this promotional strategy is to activate the role of all other concerned institutions, including schools, universities, and local nongovernmental organizations to raise consumer awareness of reducing water consumption. Finally, the strategy should promote private sector partnerships (PPP) to improve water networks and wastewater purification stations. Due to the high investment costs of such strategic but urgently needed projects, the decision-makers should create partnerships with the private sector to expedite establishing these vital projects, otherwise, none of them might be implemented with the available governmental resources.

The second main strategy is related to water distribution, namely place. In this regard, decisionand policymakers should secure financial resources (possibly through partnerships with the private sector) to improve the efficiency of the water networks, which will consequently reduce the percentage of wasted water. This is crucial for contributing significantly to solving the problem. The second intervention of this strategy is developing fair distribution of water according to the number of inhabitants and their geographical distribution. Fairness and equity in water distribution create a positive attitude among people to implement governmental policies for managing water consumption issues. This will support the actions aimed at preventing citizens from illegal digging of water wells. Finally, decision- and policymakers should consider the option of increasing water sources, including an importing option as this could contribute to solving the water shortage problem.

Regarding the pricing strategy, decision- and policymakers should consider offering incentives of lower prices to users of lower levels of consumption. In addition, it is preferable to classify water consumption prices based on use (commercial, industrial, agricultural, and residential). The third action is related to increasing the water price, which is considered a good policy to reduce water consumption by respondents. Finally, classifying the water prices according to consumption levels by applying higher prices for higher levels of consumption is considered good policy by the respondents.

The last strategy to manage water consumption is related to the product. The respondents' answers provide directions for decision- and policymakers regarding the main interventions to demarketing water consumption. Most respondents agree that excessive consumption of water was a reason to follow the policy of a programmed water cut. Accordingly, the main interventions include developing a fair policy of programmed water cuts to solve the problem of excess demand of water. Decisionmakers should recognize that the implementation of this policy is conditional on providing clean freshwater during the programmed periods of water supply. Finally, the policy of programmed water cut success depends on the fairness of applying this policy.

\section{Limitations and Future Research}

Although this study has used quantitative methodology utilizing the survey questionnaire to collect data from a relatively large sample, like other studies it still has limitations. The study only collected data from one Palestinian Territory, the Gaza Strip; the West Bank 
Territory was not included. Thus, the results cannot be generalized for all of Palestine. It is thus suggested that future study, while assessing demarketing factors to reduce water consumption, can compare all Palestinian territories within the same period of time.

The data collection in this study used self-reported data. Therefore, it is recommended that further research include multiple measures and data triangulation to more accurately assess the variables of water consumption demarketing. This study was also based on cross-sectional data collection rather than a longitudinal study to assess the impact of demarketing strategies on the level of water consumption. Future research should seek to improve on the limitations of the study. Researchers may make data collection less subjective by using other methods of obtaining data. Future research can take a longitudinal methodology rather than cross-sectional.

The study focused on the items of the marketing mix (the 4 Ps), while there were no questions (items) related to their impact on water consumption, which made finding the correlation between the variables impossible. This requires future research to focus on finding the impact of the marketing mix strategies on the consumption of water by developing items for the dependent variable (the demarketing of water consumption) to make regression analysis possible.

It would also be fruitful to pursue further research to investigate factors affecting the demarketing of water consumption for each sector (residential, industrial, agricultural, etc.) separately in more detail. Thus, water breakdown usage investigation will also be necessary as no current figures are available for the GS - for each sector in order to set strategic priorities.

\section{Acknowledgements}

Mohammed Salem would like to thank Avempace III, Erasmus Mundus, and the University of Deusto for giving him a scholarship so that he could pursue his post doc in marketing at the University of Deusto in Bilbao, Spain. Please find enclosed the research as a result of his mobility. Also, he would like to thank Mr. Nabil Sarraf for his continuous support.

\section{References}

1. MCPHAIL A. Appraisal Integrated Safeguards Data Sheet (Concept Stage) - Gaza Sustainable Water Supply ProgramP150494. Washington, D.C.: World Bank Group, 2015.

2. ROZNOWSKI S., BRUNN K., ROESNER L. Gray Water and Treated Effluent Reuse. World Environmental and Water Resources Congress 2009. 2009. Retrieved from http://ascelibrary.org/doi/abs/10.1061/41036(342)573\#sthas h.2o9J5Hf3.dpuf

3. PALESTINIAN WATER AUTHORITY (PWA). 2014 Water Resources Status Summary Report/Gaza Strip. Water Resources Directorate, 2015.

4. PALESTINIAN CENTRAL BUREAU OF STATISTICS (PCBS). Palestinians at the End of Year 2016. 2016.
5. SHARMA S., VAIRAVAMOORTHY K. Urban water demand management: prospects and challenges for the developing countries. Water and Environment Journal, 23 (3), 210, 2009.

6. DUA S., PISE A., SREEDHAR D., MANTHAN J., LIGADE V., UDUPA U. Demarketing in healthcare: Concept and approaches. Pharma Rev (Aug-Sept), 212, 2007.

7. CHAOUI M., BENTERKI A. The Demarketing: Effective Strategy to Rationalize Water Consumption. 2013.

8. LOWE B., LYNCH D., LOWE J. Reducing Household Water Consumption: A Social Marketing Approach. Journal of Marketing Management, 31 (3-4), 378, 2015. DOI: 10.1080/0267257X.2014.971044.

9. BARRETT G., WALLACE M. Demarketing Water: The Use of Home Retrofit Schemes to Reduce Household Water Consumption in Australian Capital Cities. Proceedings of $19^{\text {th }}$ ANZAM Conference, ANZAM Conference, Canberra 7-10 December 2005, 1, 2005.

10. YOUSIF R. Measuring the Effectiveness of Demarketing in Influencing Consumer Behavior of Individuals. International Journal of Business Management \& Research, 4 (5), 31, 2014.

11. GNEPA T. Consumer awareness and successful demarketing of public goods: a study of residential water conservation behavior. Journal of Academy of Business and Economics, 7 (3), 2007.

12. GLOVER S., HUNTER A. Meeting Future Palestinian Water Needs. Palestine Economic Policy Research Institute (MAS): Ramallah, Palestine. 2010.

13. COASTAL MUNICIPALITIES FOR WATER UTILITY "CMWU". Annual Report on Water Status in the Gaza Strip - Summary about Water and Wastewater Situation in Gaza Strip. 2012.

14. PASSIA. PASSIA Diary: 2011. Palestinian Academic Society for the Study of International Affairs: Jerusalem. 2011.

15. PALESTINIAN CENTRAL BUREAU OF STATISTICS (PCBS). Palestinians at the End of Year 2011. 2011. Accessed on 26, January 2012. Retrieved from :http://www. pcbs.gov.ps/Portals/PCBS/Downloads/book1815.pdf

16. THE WORLD BANK. Assessment of Restrictions on Palestinians Water Sector Development: West Bank and Gaza: Middle East and North Africa Region. 2009.

17. YUSEF A. Palestine Monitor 2009 Facebook. 2009. Accessed on 04, September 2011. Retrieved from: http:// www.palestinemonitor.org/spip/IMG/pdf/factbook_Final_ online-2.pdf

18. PALESTINIAN WATER AUTHORITY (PWA). Brief Report on the Palestinian Water. 2011.

19. WASH. Water and Sanitation in Palestine. 2013. Retrieved from http://www.ewash.org/sites/default/ files/inoptfiles/160314\%20-\%20WATER \%20AND $\% 20$ SANITATION\%20IN\%20PALESTINE.pdf

20. PALESTINIAN CENTRAL BUREAU OF STATISTICS (PCBS). Gaza Demographics. 2014. Retrieved from: http:// www.pcbs.gov.ps/site/lang_en/881/default.aspx

21. MIMI Z., ZIARA M., NIGIM H. Water conservation and its perception in Palestine - A Case Study. Water and Environmental Management. 17, 152, 2003.

22. MINISTRY OF AGRICULTURE (MOA). Agriculture Sector Strategy and Shared Vision 2011-2013. 2010. Retrieved from http://www.lacs.ps/documentsShow. aspx?ATT_ID=3991

23. PALESTINIAN WATER AUTHORITY (PWA). Water Sector Reform Plan 2016-2018. 2016. Retrieved from http:// www.pwa.ps/userfiles/server/\%D8\%AA\%D9\%82\%D8\%A 
7\%D8\%B1\%D9\%8A\%D8\%B1/WSRP\%202016-2018\%20 Final.pdf

24. TSUR Y., DINAR A. The Relative Efficiency and Implementation Costs of Alternative Methods for Pricing Irrigation Water." The World Bank Economic. 1997.

25. BOGGESS W., RONALD L., DAVID Z. Economics of Water Use in Agriculture," in Agricultural and Environmental Resource Economics. Carlson A. Gerald, David Zilberman, and John A. Miranowski, eds. New York: Oxford University Press. 319, 1993.

26. KOTLER P., LEVY S. Demarketing, yes, demarketing. Harvard Business Review, 49 (6), 74, 1971.

27. SHIU E., HASAN L., WALSH G. Demarketing tobacco through governmental policies the 4Ps revisited. Journal of Business Research, 62, 269, 2008. DOI: 10.1016/j. jbusres.2008.01.034.

28. GUPTA R. Demarketing - Tool for Social Good. 2007. www.indiamba.com (accessed February 7, 2012).
29. LAWTHER S., HASTINGS G., LOWRY R. De-marketing: Putting Kotler and Levy's ideas into practice. Journal of Marketing Management; 13, 315, 1997.

30. SAUNDERS M., LEWIS P., THORNHILL A. Research Methods for Business Students. $6^{\text {th }}$ Ed. London: Pearson Education Limited. 2012.

31. SEKARAN U. Research Methods for Business: A Skill Building Approach. John Wiley \& Sons, West Sussex. 2003.

32. KAISER H. The application of electronic computers to factor analysis. Educ Psychol Meas, 20, 141, 1960.

33. CHURCHILL G. A paradigm for developing better measures of marketing constructs. Journal of Marketing Research, 16, 64, 1979.

34. HAIR J., BLACK W., BABIN B., ANDERSON R. Multivariate data analysis: A global perspective, ( $7^{\text {th }}$ ed.). Englewood Cliffs: Prentice Hall. 2010. 